\title{
If Parents Establish a No-Smoking Agreement With Their Offspring, Does This Prevent Adolescents From Smoking? Findings From Three Dutch Studies
}

\author{
Endy A. W. den Exter Blokland, PhD \\ Rutger C. Engels, PhD \\ Zeena Harakeh, $\mathrm{PhD}$ \\ William W. Hale III, PhD \\ Wim Meeus, PhD
}

\begin{abstract}
Data from three studies were used to investigate whether the establishment of a no-smoking agreement is related to lower odds of adolescent smoking. The prevalence of a no-smoking agreement was first explored by using a national sample involving 4,501 Dutch adolescents. Second, data from a longitudinal study among 595 early adolescents and their parents were used to test whether establishing a no-smoking agreement prevents adolescents from smoking. Third, the authors tested among 856 early- and mid-adolescents and their parents, whether in addition to the establishment of a no-smoking agreement, the frequency and quality of communication on smoking issues had an effect on adolescent smoking. The findings do not support that establishing a no-smoking agreement is an effective deterrent with regard to adolescent smoking. Parents who want to prevent smoking might consider focusing their efforts on establishing a good quality of communication on smoking issues whereas parents who just talk a lot about smoking issues without considering the quality of their communication might do more harm than good.
\end{abstract}

Keywords: adolescent; communication; smoking; smoking-specific parenting

Recently research has focused on antismoking socialization as a specific way parents might prevent onset of smoking in their offspring. These studies have shown, for example, that restrictive parental policies (Henriksen \& Jackson, 1998), establishing no-smoking rules at home, warnings about the effects of smoking (Jackson, 1997), responding constructively when parents find out that their child experiments with

Endy A. W. den Exter Blokland, Utrecht University, The Netherlands. Rutger C. Engels, Radboud, University of Nijmegen, The Netherlands. Zeena Harakeh, William W. Hale III, and Wim Meeus, Utrecht University, The Netherlands.

Address correspondence to Endy A. W. den Exter Blokland, PhD, Research Centre Adolescent Development, Faculty of Social Sciences, Utrecht University, P.O. Box 80140, 3508 TC Utrecht, The Netherlands; phone: +31-30-253-1920; e-mail: e.denexterblokland@uu.nl.

Health Education \& Behavior, Vol. 36 (4): 759-776 (August 2009)

DOI: $10.1177 / 1090198108330000$

(C) 2009 by SOPHE 
smoking (den Exter Blokland, Hale, Meeus, \& Engels, 2006; Engels \& Willemsen, 2004), and a constructive way of communicating about smoking issues (Harakeh, Scholte, De Vries, \& Engels, 2005; Otten, Harakeh, Vermulst, Van Den Eijnden, \& Engels, 2007) have preventive effects on adolescent smoking.

In the Netherlands, many parents establish a no-smoking agreement with their children when the children reach their teenage years. This is a popular way among parents to try to prevent children from starting to smoke. Harakeh et al. (2005) reported that one out of three Dutch parents have established such an agreement with their children. This agreement generally implies that parents promise their children a substantial gift (e.g., money, lessons for a driver's license) if they do not smoke until they become adults (i.e., reach the age of 18). In their prevention program, STIVORO, the Dutch organization for smoking prevention and education, strongly advises parents to establish such a nosmoking agreement with their offspring (www.stivoro.nl). However, to our knowledge there is no empirical evidence for the effectiveness of a no-smoking agreement in families. Furthermore, a well-known, widely adopted primary prevention campaign conducted at secondary schools in the Netherlands (as part of the European Smoke-free Class competition) starts with the assumption that students in school classes should make very explicit no-smoking agreements (www.stivoro.nl). It is essential to gather empirical support for the effectiveness of such no-smoking agreements, because, if it actually prevents children from smoking, it is a simple and real tool that both parents and schools can offer: Make a clear agreement with young children!

In the vast majority of families, parents do not regularly discuss the issue of smoking as shown in European (Engels \& Willemsen, 2004; Harakeh et al., 2005) and North American studies (Ennett, Bauman, Foshee, Pemberton, \& Hicks, 2001). It is possible that some parents consider settling a no-smoking agreement a relatively simple tool to deal with the issue of smoking; such an agreement is less demanding than talking regularly about the pros and cons of smoking. If many parents, who establish such an agreement, do not engage in other strategies to deal with adolescent smoking, such as discussing the issue of smoking frequently and constructively, it might not be effective. In addition, parents who smoke themselves find it more difficult to raise the topic of smoking and are consequently less often engaged in antismoking socialization efforts, such as warning their children of the dangers of smoking, and setting house rules (den Exter Blokland et al., 2006; Harakeh et al., 2005; Jackson, 1997). In the current study, we will test what kinds of parents (smoking or nonsmoking, and with or without an adolescent who already started smoking or not) establish a no-smoking agreement with their child. Furthermore, in addition to making a no-smoking agreement, parents may reduce smoking in their offspring by frequently and constructively discussing smoking issues at home (see Ennett et al., 2001; Jackson \& Henriksen, 1997). Therefore, we will rigorously test whether in addition to a no-smoking agreement communication about smoking issues has a positive effect on the reduction of adolescent smoking.

The current article will focus on the effectiveness of a no-smoking agreement between parent and child in terms of the odds that adolescents will start smoking. We use three data sets including adolescents and their parents to answer our research question. First, we explore the prevalence of the no-smoking agreement by using data from a national representative sample of 4,501 Dutch adolescents (Study 1). In this data set, we further examine cross-sectionally whether parents, who establish such a no-smoking agreement, are less likely to have smoking adolescents. Second, in a short-term longitudinal study among 595 early adolescents and their parents, we test whether establishing a no-smoking agreement actually prevents adolescents from smoking (Study 2). Third, in a longitudinal study 
among 856 early- and mid-adolescents and their parents, we test (a) whether parents, who implement a no-smoking agreement, are less likely to have children who smoke, (b) what kind of parents are more likely to implement an agreement, and (c) whether frequency and quality of communication on smoking issues at home has an additive effect on adolescent smoking over and above the effect of a no-smoking agreement (Study 3).

The use of three separate data sets allows us to (a) cross-sectionally obtain a valid estimate of the prevalence of the nonsmoking agreement and to examine its association with adolescent smoking in a large and representative sample, examine the age of the adolescent when the agreement was made and until what age the agreement must be kept, (b) test associations between the nonsmoking agreement and adolescent smoking longitudinally within a 1-year interval, and (c) test these associations longitudinally within a 2-year interval with two adolescents from the same family, which allows us to study the group of adolescents who are more or less at the starting point of the nonsmoking agreement and the group who are closer to the final period of the agreement. Additionally, this data set allows us to examine the role of two separate aspects of parental communication with regard to smoking, namely frequency and quality. Finally, all analyses will be tested for the interaction with parental smoking status.

\section{STUDY 1: PREVALENCE OF THE NO-SMOKING AGREEMENT AND ITS ASSOCIATIONS WITH ADOLESCENT SMOKING}

In a sample of 4,501 Dutch adolescents, we explored the prevalence of the no-smoking agreement and examined whether parents who establish such a no-smoking agreement are less likely to have smoking adolescents.

\section{Method}

The respondents are a representative national sample of the Dutch youth population between the ages of 10 and 19 years (for more details, see den Exter Blokland, Engels, Hale, Meeus, \& Willemsen, 2004). STIVORO, the Dutch organization for smoking prevention and education, conducted this survey to monitor the development of smoking behavior among Dutch adolescents. The data were gathered in March and April 2000 by the Dutch research bureau NIPO (www.nipo.nl). Interviews with respondents conducted by trained interviewers of the NIPO took place at the schools with permission of the school board. The interviewers carried out additional face-to-face interviews with the aid of a laptop computer and without the presence of teachers, parents, or other persons during the interview of the adolescent. Adolescents not attending school were interviewed at their homes. The interviewers guaranteed total anonymity of the respondents.

A total of 4,501 adolescents took part in this study; $50.6 \%$ of the sample consisted of boys. The data included 10 age groups: a group of 10-year-olds represented $4.2 \%$ of the total sample; 11-year-olds, $10.9 \%$; 12-year-olds, $16.4 \%$; 13-year-olds, $13.1 \%$; 14-year-olds, $11.0 \%$; 15-year-olds, $10.0 \%$; 16-year-olds, $8.8 \%$; 17-year-olds, $9.1 \%$; 18 -year-olds, $7.5 \%$; and 19-year-olds, $8.9 \%$. Elementary schoolchildren formed $25.2 \%$ of the sample; special education, 5.5\% (schools for children with learning disabilities); and first grade of secondary education, $10.1 \%$. From second grade on the sample could be differentiated into low-level high school (22.4\%), middle-level high school (16.8\%), and the highest level of secondary school in the Netherlands, namely, preparatory 
university education (13.4\%). Finally, $5.8 \%$ of the sample had jobs, and $0.6 \%$ was unemployed and did not attend school.

\section{Measures}

No-Smoking Agreement. Respondents had to indicate whether they had made a nosmoking agreement, the age at which they had made the agreement and with whom, and until what age they had to keep this agreement.

Adolescent Smoking. The two dependent measures, adolescents' ever smoking and current smoking, were based on self-reported smoking. Respondents were first asked whether they had ever smoked, even one puff (cf. Engels, Knibbe, \& Drop, 1999). Never smokers were coded 0 , ever smokers were coded 1 . To construct the second variable (current smoking), a 7-point ordinal scale was used, ranging from never smoking, several levels of experimentation (quit smoking, tried smoking, smoked less than once a month; not weekly but once a month, not daily but once a week) up to daily smoking (Engels, Vitaro, den Exter Blokland, De Kemp, \& Scholte, 2004). Never smokers and smokers who had not smoked in the last month were coded 0, current smokers, those who had smoked the last month, were coded 1.

Parental smoking status was measured by asking the respondent whether their father or mother currently smoked or not. Each parent was classified into one of two groups on the basis of their smoking status: nonsmoker or current smoker. Two levels of parental smoking were constructed: (a) both parents do not smoke and (b) at least one parent is a smoker. Recently, Harakeh, Engels, De Vries, and Scholte (2006) have shown that adolescents can provide highly reliable reports of parents' current smoking behavior (see also Vink, Willemsen, Engels, \& Boomsma, 2003).

\section{Results}

Of the adolescents, a total of 1,377 (30.6\%) indicated they had a no-smoking agreement with their parents. There were no differences in this respect between boys and girls. Of these agreements, $28.6 \%$ were made before the age of 10 years, $22.5 \%$ at the age of 10 years, $13.7 \%$ at the age of 11 years, $21.7 \%$ at the age of 12 years, and $13.5 \%$ at the age of 13 years or older. Most adolescents $(66.7 \%)$ reported that they had to keep their agreement until the age of 18 , a total of $15.5 \%$ until the age of 16 and 17 , and $17.8 \%$ until the age of 19 through 22 . In $90 \%$ of the cases, the no-smoking agreement was made with the parents. In the remaining $10 \%$, the agreement was made with other family members or with the school. With respect to adolescent smoking, 53.8\% of the adolescents indicated having ever smoked and $25.5 \%$ had smoked in the past month. Of the sample, $51.6 \%$ indicated having at least one smoking parent.

The logistic regression analyses in Table 1 show the relationship between having a no-smoking agreement and adolescent ever smoking and current smoking, respectively. For reasons of comparability with the two other studies, some background characteristics were included as control variables: gender, age, educational level, and parental smoking status. As a result of the broader age range of this sample, educational levels of the respondents were categorized into more categories than the other two studies presented further on, namely: (a) low level of secondary school, (b) middle level of secondary school, (c) high level of secondary school, (d) last year of elementary and first year of secondary school, 
Table 1. Cross-Sectional Associations Between No-Smoking Agreement and Adolescent Ever and Current Smoking: Logistic Regression Analyses in a Representative Dutch Sample of 4,501 Adolescents

\begin{tabular}{|c|c|c|c|c|c|c|}
\hline & \multicolumn{3}{|c|}{ Ever Smoking } & \multicolumn{3}{|c|}{ Current Smoking } \\
\hline & \multirow[b]{2}{*}{ OR } & \multicolumn{2}{|c|}{ CI } & \multirow[b]{2}{*}{ OR } & \multicolumn{2}{|c|}{ CI } \\
\hline & & Lower & Upper & & Lower & Upper \\
\hline \multicolumn{7}{|l|}{ Step 1} \\
\hline \multicolumn{7}{|l|}{ Gender } \\
\hline Male & 1.00 & & & 1.00 & & \\
\hline Female & $.87 *$ & 1.01 & 1.31 & .96 & .89 & 1.22 \\
\hline Age $^{a}$ & $1.37 * * *$ & 1.31 & 1.43 & $1.50 * * *$ & 1.42 & 1.59 \\
\hline \multicolumn{7}{|l|}{ Educational level } \\
\hline Low secondary education & 1.00 & & & 1.00 & & \\
\hline Middle secondary education & $.62 *$ & .49 & .78 & $.53 * * *$ & .41 & .67 \\
\hline High secondary education & $.41 * * *$ & .32 & .53 & $.32 * * *$ & .24 & .42 \\
\hline $\begin{array}{l}\text { Last year elementary } \\
\text { and first year secondary }\end{array}$ & $.59 * * *$ & .48 & .73 & $.39 * * *$ & .29 & .51 \\
\hline Not attending school (working) & .79 & .54 & 1.15 & $.63^{* *}$ & .45 & .89 \\
\hline Special education & .77 & .57 & 1.04 & .77 & .54 & 1.10 \\
\hline \multicolumn{7}{|l|}{ Parental smoking status } \\
\hline Nonsmoking parents & 1.00 & & & 1.00 & & \\
\hline At least one smoking parent & $2.32 * * *$ & 2.03 & 2.65 & $2.28 * * *$ & 1.95 & 2.68 \\
\hline \multicolumn{7}{|l|}{ Step 2} \\
\hline No-smoking agreement ${ }^{\mathrm{b}}$ & .92 & .80 & 1.07 & $.54 * * *$ & .45 & .65 \\
\hline
\end{tabular}

NOTE: $\mathrm{OR}=$ odds ratio; $\mathrm{CI}=95 \%$ confidence interval.

a. Age between 10 and 19 years.

b. Both analyses tested for the interaction between parental smoking and no-smoking agreement reached significance. For ever and current smokers, $\mathrm{OR}=.67, p<.01$ and $\mathrm{OR}=.60, p<.01$, respectively. Only for smoking parents, having a no-smoking agreement was associated with reduced likelihood of ever smoking $(\mathrm{OR}=.77, p<.01)$. Current smoking: having a no-smoking agreement was more strongly associated with a reduced likelihood of adolescent current smoking for smoking parents $(\mathrm{OR}=.45, p<.001)$ as compared with the group of nonsmoking parents $(\mathrm{OR}=.72, p<.05)$.

$* p<.05 . * * p<.01 . * * * p<.001$.

(e) the working and unemployed respondents were grouped as "not attending school," and finally (f) special education.

The findings demonstrated that having a no-smoking agreement was not related to ever smoking, but was negatively related to current smoking. So adolescents, who had a no-smoking agreement with their parents, were less likely to be current smokers. Being male, older, and having a lower level of education was related to higher odds of ever smoking. Being young, having a higher level of education, or being in the last year of elementary/first year secondary school, or not attending school was related to lower odds of current smoking.

Furthermore, parental smoking was related to higher involvement in ever and current smoking among adolescents. Additional analyses were conducted to test whether the associations between no-smoking agreement and adolescent smoking differ 
between smoking and nonsmoking parents. This was done by including interaction terms in the final step of the equation (cf. Aguinis, 2004). For both analyses the interaction was significant (odds ratio $[\mathrm{OR}]=.67, p<.01$ and $\mathrm{OR}=.60, p<.01$, respectively). Further examination showed that only for families with at least one smoking parent, having a no-smoking agreement reduced the chances that their child was an ever smoker $(\mathrm{OR}=.77, p<.01)$. With regard to current smoking, it turned out that having a no-smoking agreement was related to a lower likelihood of current smoking in the case that there was at least one smoking parent $(\mathrm{OR}=.45, p<.001)$ as compared with the group of nonsmoking parents $(\mathrm{OR}=.72, p<.05)$.

\section{STUDY 2: DOES A NO-SMOKING AGREEMENT ACTUALLY PREVENT ADOLESCENTS FROM SMOKING? A SHORT-TERM LONGITUDINAL STUDY AMONG 595 EARLY ADOLESCENTS AND THEIR PARENTS}

\section{Method}

The sample consisted of 545 two-parent families and 50 single-parent families that had one adolescent child in the first year of secondary education (sample is not representative compared to Study 1; for more details see den Exter Blokland et al., 2006; Engels et al., 2004; Harakeh, Scholte, De Vries, Vermulst, \& Engels, 2004). Two selfreport questionnaires were used; one questionnaire that was administered to the children at school twice with a 1-year interval (T1 took place in winter 2000 and T2 in winter 2001) under supervision of a teacher, and a one-time questionnaire that was sent to the parents at the same time that the first wave was conducted among adolescents at school. A total of six Dutch high schools participated in the study, differentiating four types of education, namely trade schools (14.3\%), lower level high schools (24.7\%), middle-level high schools (19.0\%), and finally preparatory schools (42.0\%). In Study 2 (and 3), the educational level is discriminating between capabilities in terms of learning on the level for the group with middle and high education as compared with the group with lower education, which is more focused on skills needed for professions that require hand labor. In a way, the educational level therefore can be viewed as a distal measure of social class.

The mean adolescent age at $\mathrm{T} 1$ was 12.3 years $(S D=.52)$, ranging from 10 to 14 years. Fifty-three percent $(N=315)$ of the adolescents were males. Most of the adolescents had the Dutch nationality (97\%). The majority of the adolescents (92\%) lived with both their parents, $6 \%$ lived only with their mother, $1 \%$ lived only with their father, and $1 \%$ was adopted. With respect to parental smoking as reported by the adolescent, $62.7 \%$ of the families consisted of nonsmoking parents, $25.5 \%$ of one smoking parent, and $11.8 \%$ of two smoking parents. We employed adolescent reports on their mother's and father's smoking behavior separately to differentiate between smoking and nonsmoking parents. In the analyses we contrasted between nonsmoking parents and "at least one smoking parent." This enabled us to account for single-parent families.

We sent 1,380 letters and questionnaires to the parents' homes and a total of 712 (52\%) parents returned the questionnaire that was only administered at T1. Only one parent had to fill in the questionnaire. In $75 \%$ of the cases, the mother completed the questionnaire. Analyses are restricted to those parent-adolescent pairs that we have complete data on, resulting in the loss of 117 parental responses because of the absence 
of their child at the school testing. There were, however, no apparent differences in the distribution of parental reports of the no-smoking agreement between the initial complete set of parental data $(N=712)$ and the data used for analyses $(N=595)$, namely 211 parents $(29.6 \%)$ versus 164 parents $(27.6 \%)$ indicated to have a no-smoking agreement, respectively.

\section{Measures}

Adolescent and parental smoking statuses were measured in the first and second wave school-questionnaires. Whether families had made a no-smoking agreement was only assessed among parents at the first wave. Parental smoking and questions regarding a no-smoking agreement were the same as employed in Study 1.

Adolescent Smoking. Adolescents' smoking status was based on self-reported smoking at both waves. An ordinal scale was used, ranging from never smoking to current smoking (Kremers, Mudde, \& de Vries, 2001; see Study 1).

\section{Results}

\section{Descriptives}

Of the families, $27.6 \%$ of the parents reported having a no-smoking agreement with their child. A total of $12.8 \%$ reported to have made this agreement when their child was less than 10 years of age, $35.9 \%$ when their child was 10 years, $20.5 \%$ when their child was 11 years, and $30.8 \%$ when their child was 12 or 13 years. For the majority of the adolescents (79.9\%), the agreement is made until they reach the age of 18 . In the vast majority, the agreement is made with one or both parents $(92.6 \%)$, in other cases with the school (1.2\%), another family member $(4.9 \%)$, or someone else $(1.2 \%)$.

Concerning smoking, $25.1 \%$ of the adolescents reported having ever smoked at T1 as compared with $39.8 \%$ at T2. At T2, 11.4\% reported to have smoked in the past month (current smokers).

\section{Does a No-Smoking Agreement Have a Longitudinal Effect on Adolescent Smoking?}

The longitudinal analyses presented in Table 2 predicting ever smoking (i.e., differentiating never smokers versus those who at least smoked once) and current smoking (differentiating non-current smokers versus current smokers [i.e., those who smoked at least once in the past 4 weeks]) showed no predictive associations between a no-smoking agreement and adolescent smoking after controlling for initial smoking at T1, age, gender, educational level, and parental smoking. Additional analyses were conducted to test whether parental smoking might possibly affect the associations between no-smoking agreement and adolescent smoking. However, no interaction effects were found.

These analyses do not support that in this sample of early adolescents having a no-smoking agreement is associated with a reduction in smoking. Additionally, we repeated these analyses for the group of adolescents who were never smokers at T1 (not presented in the Tables). These analyses were a means of testing predictors of onset of smoking but no effects were found. 
Table 2. Longitudinal Associations Between No-Smoking Agreement at T1 and Early Adolescent Smoking 1 Year Later: Logistic Regression Analyses in a Sample of 595 Early Adolescents and Their Parents

\begin{tabular}{|c|c|c|c|c|c|c|}
\hline & \multicolumn{3}{|c|}{ Ever Smoking } & \multicolumn{3}{|c|}{ Current Smoking } \\
\hline & \multirow[b]{2}{*}{ OR } & \multicolumn{2}{|c|}{ CI } & \multirow[b]{2}{*}{ OR } & \multicolumn{2}{|c|}{ CI } \\
\hline & & Lower & Upper & & Lower & Upper \\
\hline \multicolumn{7}{|l|}{ Step 1} \\
\hline \multicolumn{7}{|l|}{ Gender } \\
\hline Male & 1.00 & & & 1.00 & & \\
\hline Female & 1.48 & .96 & 2.28 & 1.70 & .96 & 3.02 \\
\hline Age & .92 & .60 & 1.40 & 1.05 & .59 & 1.87 \\
\hline \multicolumn{7}{|l|}{ Educational level } \\
\hline Low & 1.00 & & & 1.00 & & \\
\hline Middle & .56 & .31 & 1.02 & $.45^{*}$ & .19 & 1.03 \\
\hline High & $.58 *$ & .36 & .94 & $.42 * *$ & .22 & .83 \\
\hline \multicolumn{7}{|l|}{ Parental smoking status } \\
\hline Nonsmoking parents & 1.00 & & & 1.00 & & \\
\hline $\begin{array}{l}\text { At least one } \\
\text { smoking parent }\end{array}$ & 1.40 & .88 & 2.17 & 1.04 & .58 & 1.87 \\
\hline $\begin{array}{l}\text { Adolescent smoking } \\
\text { at } \mathrm{T} 1\end{array}$ & $38.59 * * *$ & 20.18 & 73.76 & $7.50 * * *$ & 4.14 & 13.57 \\
\hline \multicolumn{7}{|l|}{ Step 2} \\
\hline No-smoking agreement & .90 & .55 & 1.47 & 1.01 & .55 & 1.86 \\
\hline
\end{tabular}

NOTE: $\mathrm{OR}=$ odds ratio; $\mathrm{CI}=95 \%$ confidence interval. All presented estimates are those in the final step of the equation.

$* p<.05 . * * p<.01 . * * * p<.001$.

\section{STUDY 3: NO-SMOKING AGREEMENT AND PARENTAL COMMUNICATION}

In a sample of 428 families we test (a) whether parents who implement a no-smoking agreement are less likely to have children who smoke, (b) what kinds of parents are more likely to implement an agreement, and (c) whether frequency and quality of communication on smoking issues at home have an added effect on adolescent smoking over and above the effect of a no-smoking agreement.

\section{Method}

\section{Participants}

Families participated in a longitudinal study, "Family and Health," which had three waves with a 1-year interval between each wave. To address the research questions however, only Wave 1 and Wave 3 data will be used because we wanted to maximize the time between the no-smoking agreement and the dependent measure, adolescent smoking.

The addresses of families with both parents and two adolescents (13 to 16 years) were selected from the registers of 22 municipalities in the Netherlands. The families were approached between November 2002 and April 2003. A total of 428 Dutch families 
were selected to participate at baseline. A full family design was used: Each family consisted of a mother, father, and two adolescents between the ages of 13 and 16 years (for more details see Harakeh et al., 2005; Van Der Vorst, Engels, Dekovic, Van Leeuwe, \& Meeus, 2005). Families had to meet the following inclusion criteria to participate in our study: The adolescents in the families were biologically related to each other and the mother and father were the biological parents of these adolescents; parents were married or living together during the project (two families had to be excluded from the third measurement because the parents were divorced or not living together any more), and the two adolescents participating in each family were neither twins nor mentally or physically disabled.

At baseline, oldest adolescents' ages ranged from 14 to 17 years $(M=15.22 ; S D=$ $0.60)$, youngest adolescents' ages ranged from 13 to 15 years $(M=13.36 ; S D=0.50)$, mothers' ages ranged from 35 to 56 years $(M=43.82 ; S D=3.57)$, and fathers' ages ranged from 37 to 62 years $(M=46.18 ; S D=4.00)$. Males and females were equally distributed among the two adolescent cohorts: $52.8 \%$ of the oldest adolescents were male and $47.7 \%$ of the youngest adolescents were male. The educational level of the oldest adolescents was distributed as follows in this sample: $30.9 \%$ attended lower-level education (i.e., preparatory secondary school for technical and vocational training); 29.3\% attended middle-level education (i.e., preparatory secondary school for college); and $39.6 \%$ high-level education (i.e., preparatory secondary school for university).

With respect to the educational level of the youngest adolescents, 36.4\% attended lower-level education, $36.7 \%$ attended intermediate-level education, and $26.5 \%$ attended high-level education.

\section{Procedure}

We sent letters and informed consent forms to 5,602 families to invite them to participate in our longitudinal study; 981 families responded. From these families, 96 turned out not to meet the inclusion criteria or indicated that they were not willing to participate. The remaining 885 families were phoned to check whether they met all the entry criteria. However, 120 families could not be approached or contacted. The remaining 765 families met the inclusion criteria. To ensure an equal distribution of the educational level of adolescents and an equal number of all the possible sibling dyads (i.e., boy-boy, girlboy, boy-girl, girl-girl), 428 families were selected to participate. The initial response rate was not high; this was mainly due to the fact that we had various criteria families had to fulfill in order to get included in the study, all 4 family members had to participate, and they had to be willing to participate in a longitudinal study.

Interviewers visited all the families at home at baseline. The baseline was between November 2002 and April 2003 (T1; $N=428$ ). The follow-up was 2 years later (T2; $N=402$ ). Attrition between the waves was low: In total, 26 families dropped out of the study, because they did not wish to participate anymore, because they had moved, or because the parents had divorced. During the interviewer's home visits, each family member completed the questionnaire individually and separately. The questionnaire took about 90 minutes to complete. At each measurement wave, each family received 30 Euros when all four family members had filled in the questionnaires. At the end of the longitudinal project five traveler's checks of 1,000 Euros each were raffled between families who participated in all three waves. 


\section{Measures}

No-smoking agreement, parental, and adolescent smoking were assessed with similar questions as in Study 2.

Frequency of Smoking-Specific Communication. This factor refers to how often in the past 12 months the mother and father talked with their adolescents about issues concerning smoking at T1. This scale is similar to the scale used by Ennett et al. (2001) to assess smoking-specific communication, and consisted of eight items (e.g., "During the past 12 months, how many times did your mother talk to you about how to resist peer pressure to use tobacco?" or, "During the past 12 months, how often did your mother tell you that you are not allowed to smoke?"). Response categories ranged from 1 (never) to 5 (very often). Cronbach's alpha was .86. We used adolescent reports to calculate the mean score of the scales for both father and mother communication.

Quality of Smoking-Specific Communication. We assessed the quality of smokingspecific communication at $\mathrm{T} 1$. This factor represented the quality of communication about smoking between parent and adolescent (Harakeh et al., 2005). This scale consisted of six items (e.g., the questionnaire version for adolescents was "My mother and I are interested in each other's opinion about smoking" or "When I talk with my mother about smoking I feel that she takes me seriously") on a 5-point scale. Response categories ranged from 1 (completely not true) to 5 (completely true). Cronbach's alpha was .84. We used adolescent reports to calculate the mean score of the scales for both father and mother.

\section{Results}

\section{Descriptives}

Of the adolescents, $36.4 \%$ of the youngest adolescents $(N=156)$ and $34.4 \%$ of the oldest adolescents $(N=147)$ indicated to have a no-smoking agreement with their parents. There were no differences in this respect between boys and girls. The average age when this agreement was established was 9.98 years $(S D=2.12)$ according to the youngest adolescent and 11.18 years $(S D=1.97)$ according to the oldest adolescent. Most adolescents reported that they had to keep this agreement until the age of 18; $67.8 \%$ of the youngest adolescents, and $74.6 \%$ of the oldest adolescents.

In $25 \%$ of the cases parents make this agreement with both siblings, in $22.7 \%$ of the cases only with one sibling. In $224(52.3 \%)$ families there is a no-smoking agreement with neither of the adolescents. This has to do with the fact that the no-smoking agreement is not consequently applied to both children within one family.

Most adolescents reported having a no-smoking agreement with their parents at both measurements; $84 \%$ of the youngest adolescents $\left(\chi^{2}(1,388)=165.76, p<.001\right)$, and $86 \%$ of the oldest adolescents $\left(\chi^{2}(1,385)=183.83, p<.001\right)$ reported having a no-smoking agreement at both time points.

With respect to smoking, $35.7 \%$ of the youngest children indicated ever smoking at $\mathrm{T} 1$ and $48.5 \%$ at $\mathrm{T} 2$. A total of $5.6 \%$ reported to be a current smoker at $\mathrm{T} 1$ and $15.9 \%$ at T2. Of the oldest adolescents, $48 \%$ reported ever smoking at $\mathrm{T} 1$ and $54.7 \%$ at $\mathrm{T} 2$. Furthermore, $10.7 \%$ reported being a current smoker at $\mathrm{T} 1$ and $17.7 \%$ at $\mathrm{T} 2$. The correlation at $\mathrm{T} 1$ between both siblings smoking status was considerable $(r=.35, p<.001)$. 
We therefore ran the analyses again with the inclusion of the oldest siblings' smoking status at $\mathrm{T} 1$ to see whether this had any effect on the youngest sibling with regard to ever and current smoking at T2 but no significant contribution was found whereas all the other significant effects remained identical in strength and direction. However, for reasons of comparability with both other studies, sibling smoking status has not been included in the analyses presented.

Which Parents Establish a No-Smoking Agreement With Their Children? First, we tested whether some parents are more likely to establish a no-smoking agreement than others. We examined cross-sectionally whether parents with smoking adolescents are more likely to establish a no-smoking agreement (not presented in the tables). We did not find any indication for the assumption that parents with adolescents who had already initiated smoking are more likely to establish a no-smoking agreement at T1. Furthermore, we did not find an association between parental smoking and having a no-smoking agreement at T1. Furthermore, parents who have established a no-smoking agreement with their children may be less or more likely to be involved in communication on smoking matters. In both adolescents, we did not find any differences in quality of communication between parents who had a no-smoking agreement or not. However, parents who had a no-smoking agreement discussed smoking issues with their children more frequently $\left(t_{\text {oldest adolescent }}(416)=4.05, p<.001 ; t_{\text {youngest adolescent }}(416)=5.53, p<.001\right)$. In sum, except for the frequency of communication on smoking issues, which was associated with the establishment of a no-smoking agreement, we did not find an indication that the establishment of a no-smoking agreement depended on parental smoking status: having children who already smoke or a lack of constructive communication with their children on smoking matters.

Does a No-Smoking Agreement Have a Longitudinal Effect on Adolescent Smoking? With hierarchical logistic regression analyses we examined whether a no-smoking agreement affected adolescent smoking in the long run (Table 3). Separate analyses were carried out for the youngest and oldest adolescents in the family, and for ever smoking and current smoking. In all analyses, we controlled for possible confounders in the first step. Moreover, in these analyses we included adolescent smoking at T1 in the first step, so our prospective findings can be interpreted in terms of predicting changes in smoking between $\mathrm{T} 1$ and $\mathrm{T} 2$.

In three out of four longitudinal analyses presented in Table 3, no association was found between having a no-smoking agreement at T1 and adolescent smoking at T2. In one analysis (oldest adolescent predicting ever smoking), we even found that when parents had a no-smoking agreement adolescents were more likely to smoke 2 years later.

In a second series of analyses presented in Table 4, we examined whether quality and frequency of communication concerning smoking at $\mathrm{T} 1$ added to the prediction of adolescent smoking at T2 (Table 4). The T1 correlations between the quality and frequency measures of communication, controlled for the no-smoking agreement, for both the youngest and oldest adolescent were low (for the youngest adolescent: $r=.13, p=.01$ and for the oldest adolescent: $r=.05, p=.27$, respectively). A clear pattern emerged resulting in strong, robust effects of quality of communication on adolescent smoking at T2. Adolescents who reported a low quality of communication on smoking with their parents were up to three times more likely to smoke 2 years later as compared with adolescents who reported a high quality of communication. Frequency of communication in contrast was positively associated with smoking; parents who talked often on smoking issues were 


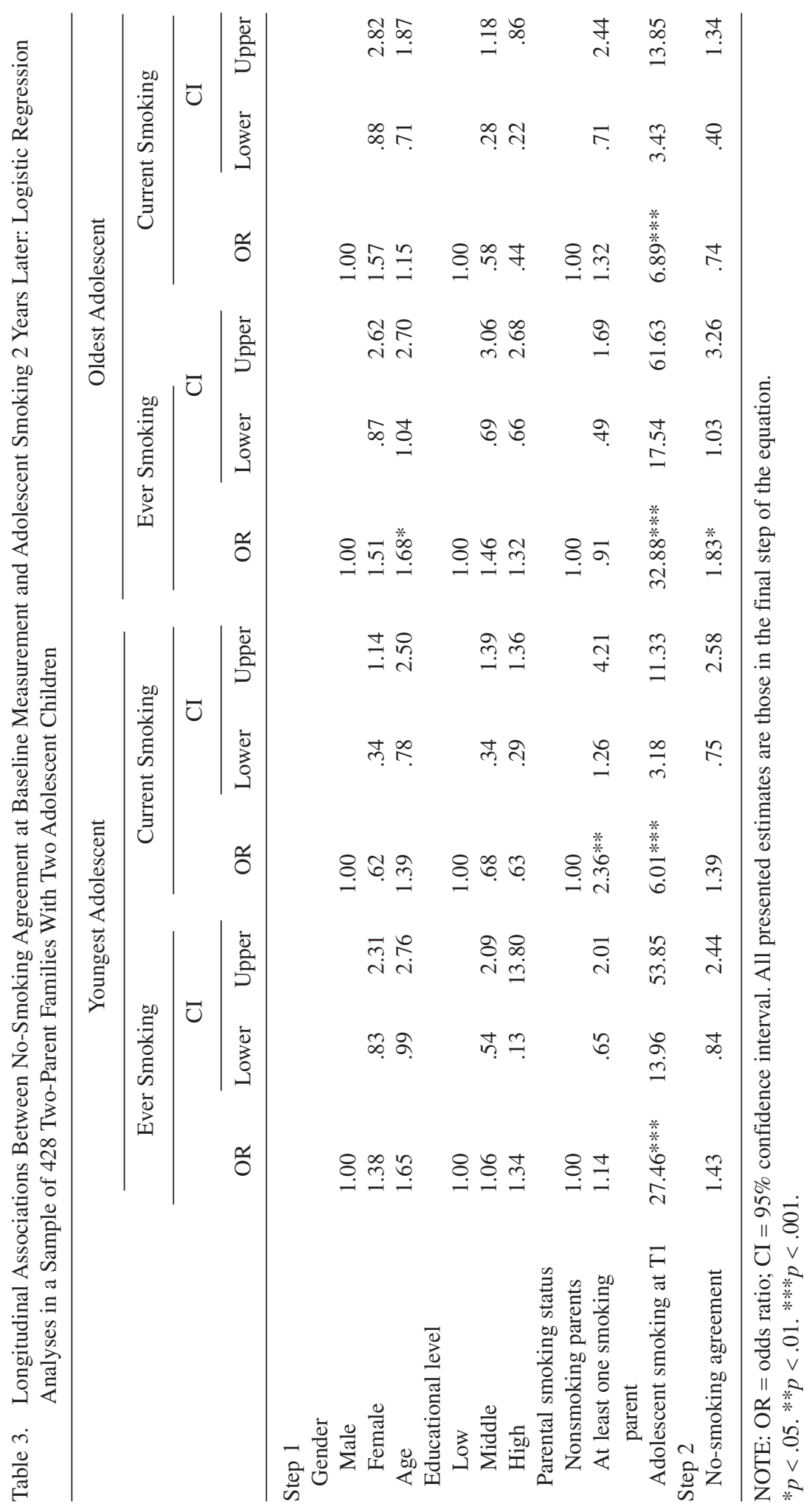




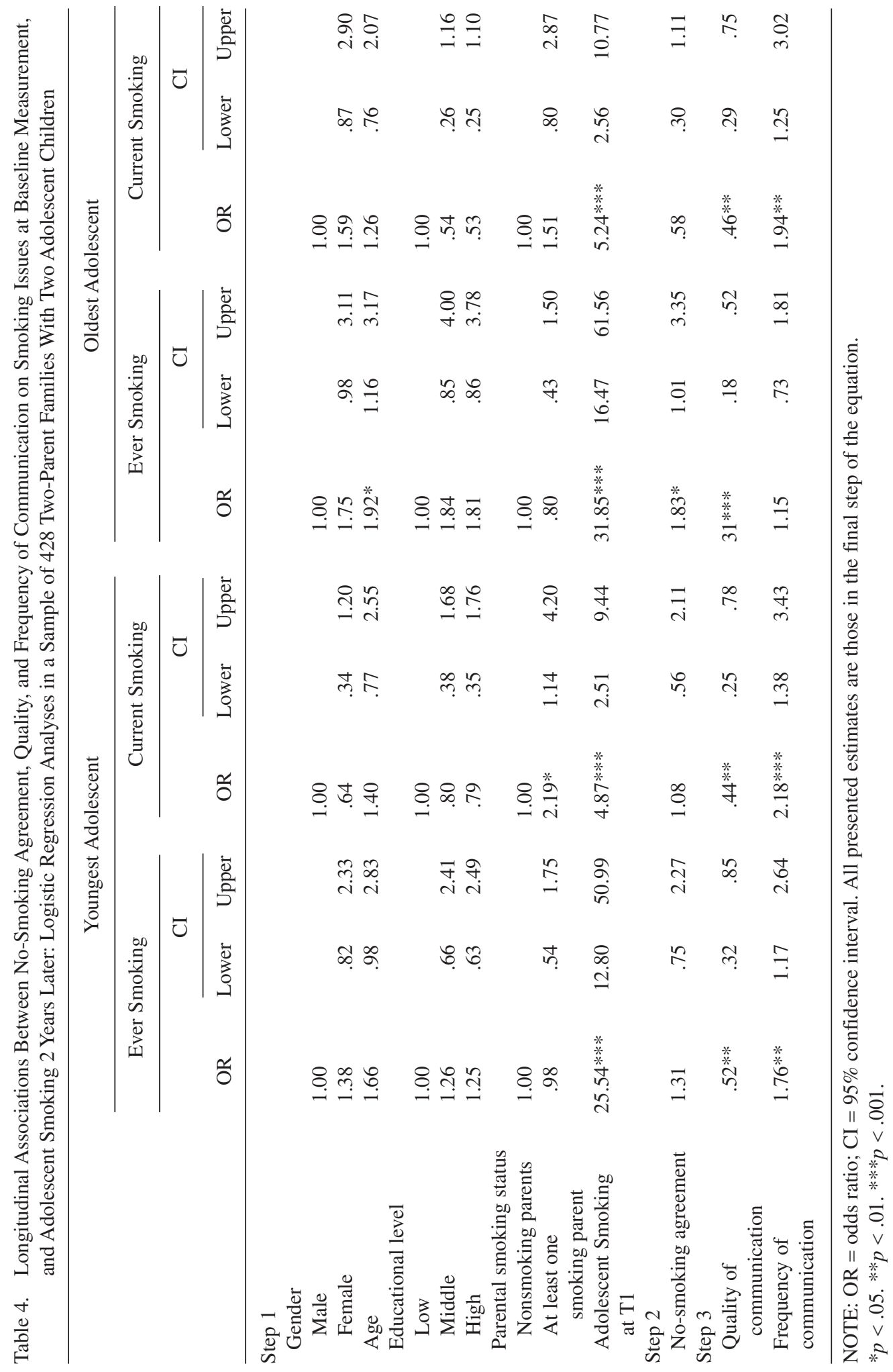


more likely to end up with smoking children. In all analyses we corrected for the strong effects of smoking status at T1, stressing the relevance of quality of communication concerning smoking as a tool for parents to reduce smoking in their offspring.

Additionally, we repeated these analyses for the group of adolescents (youngest adolescent, $N=257$; oldest adolescent, $N=207$ ), who were never smokers at T1 (not presented in the Tables). These analyses were a means of testing predictors of onset of smoking. For the youngest adolescent we found that after controlling for age, gender, educational level, and parental smoking, having a no-smoking agreement was not associated with smoking onset $(\mathrm{OR}=1.39, p>.05)$, the quality of communication was negatively associated with smoking onset $(\mathrm{OR}=.49, p<.01)$, and the frequency of communication was positively associated with smoking onset $(\mathrm{OR}=1.65, p<.05)$. For the oldest adolescent we found no significant associations between no-smoking agreement $(\mathrm{OR}=2.06, p=.056)$ and frequency of smokingspecific communication $(\mathrm{OR}=1.1, p>.05)$ on the one hand, and smoking onset on the other. However, low quality of communication was strongly associated with smoking onset $(\mathrm{OR}=.27, p<.001)$.

Additional analyses were conducted whether associations between no-smoking agreement and adolescent smoking at T2 are moderated by parental smoking status, adolescent smoking at T1, quality of communication, and frequency of communication. We tested this by including interaction terms in the final step of the regression analyses. None of the interaction terms were significant.

\section{DISCUSSION}

The current article has investigated whether the establishment of a no-smoking agreement is an effective tool for parents to prevent their offspring from smoking. In the Netherlands, many families have such an agreement; the prevalence varies between $27.6 \%$ and $36.4 \%$ over the three studies. We used three separate data sets to test associations between a no-smoking agreement and adolescent lifetime and current smoking. In addition, we tested whether frequency and quality of parental communication on smoking issues were related to adolescent smoking.

We started from the assumption that the establishment of a no-smoking agreement is a relatively simple communication tool. Parents only have to briefly discuss the topic of smoking with their young children. By simply making the agreement—and subsequently rewarding their children when they keep the agreement- there is no further need for intensive discussion and parents might feel they have made a constructive effort in preventing their children from becoming smokers. The seeming popularity of the no-smoking agreement is probably based on the assumption that parents can be protective gatekeepers if they set clear rules, and if keeping the rules is accompanied by a substantial reward (e.g., Clark, Scarisbrick-Hauser, Gautam, \& Wirk, 1999). Surprisingly, no prior research has been conducted into the link between such a no-smoking agreement and juvenile smoking although some preventive programs stress the importance of making such an agreement.

As a tool the no-smoking agreement can be used in two ways. In the first way, the agreement is implemented to prevent future smoking in adolescents who have never smoked; hence, the goal of the agreement is to reinforce the continuation of an existing habitual pattern. In the second way, adolescents that experiment with smoking are offered the agreement with the goal of trying to change an existing pattern. From a 
behavioral viewpoint, however, these two goals are separate phenomena and both goals require different approaches to be effective (Bandura, 1986).

The cross-sectional findings of Study 1 , using a representative sample of 4,501 adolescents in the age range of 10 to 19 years, seem to indicate that the no-smoking agreement is only an effective tool in dealing with adolescent current smoking, especially for smoking parents. However, these findings merely represent cross-sectional associations and should be interpreted accordingly. For example, it might be the case that only the successful respondents with regard to the keeping of the agreement are overrepresented in this analysis, whereas those adolescents who already smoke obviously do not have the agreement or were unable to keep the agreement earlier in time.

However, longitudinally our results indicate that the no-smoking agreement is not related to lower odds of adolescent smoking. We only found partial support for change in smoking behavior, but in a direction not intended by the parents. The oldest adolescents in the third study showed an increased likelihood of smoking. Explanations why this is the case are speculative, for example, parents with children that are vulnerable with regard to smoking might be more inclined to use the no-smoking agreement. Future studies should look into a number of such alternative explanations.

It was shown that a high quality of communication on smoking matters helps parents to prevent smoking in both youngest and oldest adolescents. However, conversely, a high frequency of communication is associated with smoking; parents who often talk about smoking issues are more likely to end up with smoking children. The findings of Study 3 clearly demonstrate both the positive and the negative effects of communication on smoking issues. High-quality communication on the part of the parents has a powerful deterrent link with adolescent smoking whereas frequently raising the subject of smoking on the part of the parents has a persistent counterproductive effect on adolescent smoking (see also Harakeh et al., 2005).

Furthermore, our finding that a higher quality of parental communication as perceived by the adolescent is associated with lower likelihood of future adolescent smoking can be interpreted as being the result of good parenting; the adolescent feels comfortable to discuss the topic of smoking with his or her parents and the parents are willing to address the topic in a constructive manner. Previous research into parental communication about smoking issues has been mixed, which is much in line with our longitudinal findings that the quality of parental communication is helpful but if parents raise the issue very often it has negative repercussions (Harakeh et al., 2005). Ennett et al. (2001) suggest that when adolescents experiment with smoking, parents communicate more frequently with their children in an attempt to prevent them from continuing to smoke. However, their findings indicate that these attempts are not fruitful. Adolescents can find their parents to be nagging when the parents continue to raise the topic of smoking when the adolescent is not willing to enter into the discussion. Nagging is indicative of a lack of mutual trust and respect, which is required for a real transfer of information to take place. Nagging may also be an indication that the parents lack the necessary skills associated with good parenting.

Dishion and McMahon (1998) suggest that a high quality of communication is an important aspect in their definition of parental monitoring, which includes those behaviors that facilitate awareness of the child's activities and communicate to the child that the parent is concerned about and aware of the child's activities. Indeed, various studies among youths in the United States have shown that parental monitoring creates a climate in which children are less likely to experiment with smoking (Chassin et al., 2005; Hill, Hawkins, Catalano, Abbott, \& Guo, 2005; Kodl \& Mermelstein, 2004). Kerr, Statin, and 
Trost (1999) have added the concept of trust to this debate arguing that the concept of monitoring largely depends on the child's willingness to disclose information to the parents. They suggest that the information disclosed by the child produces a certain level of parental trust but also that trusting parents respond in such a way that children feel more free to disclose. Our findings indicate that when the adolescent experiences open communication with the parents about smoking issues in an atmosphere of trust and respect, this has a deterrent effect on future adolescent smoking. Future studies should investigate whether other caretaking mechanisms, monitoring, for example, are useful in this respect.

\section{Limitations}

One limitation of this study is that parental smoking status is determined neither at the time of the no-smoking agreement nor at follow-up in the longitudinal data. The dynamics of parental smoking might have an impact on the relationship between no-smoking agreement and adolescent smoking. To detect the influence of changes in parental smoking status however, large samples are needed in future studies.

Additionally, it would be useful to gather more information about the motivation of parents to implement the no-smoking agreement or the motivations of the adolescent to agree. We implicitly assumed that parents make the agreement with their children, but we do not know who takes the initiative, which might be relevant with regard to the adolescent's willingness to comply. For example, an adolescent with a high intention to remain a never smoker might ask his or her parents for a no-smoking agreement because the reward, although far in the future, will be easily earned. Additionally, some parents may have communicated with their children about smoking long before they have reached an age at which they are at increased risk to smoke. However, we have no measurements of these processes in childhood and therefore cannot determine whether early communication is effective in preventing smoking when the child reaches the teenage years. Another limitation with regard to communication is that only communication about smoking was measured whereas other health issues were not addressed.

Although our results indicate that the no-smoking agreement is not longitudinally associated with lower likelihood of adolescent smoking, we cannot address the question whether the impact of having a no-smoking agreement is more subtle in nature than this study examined. It has been suggested in the literature that even delaying the onset of smoking contributes to later age of regular use, lower intensity, and less difficulties in quit attempts (e.g., Chassin, Presson, Sherman, \& Edwards, 1990; Fagerstrom, 1991; Stanton, 1995), and we cannot speculate as to whether the no-smoking agreement has any impact on these phenomena. Additionally, it is even possible that if a follow-up of the respondents in the first cross-sectional study had been conducted, there might be a longitudinal preventive effect of a no-smoking agreement.

We regretfully have no longitudinal data of the three studies presented by which we can determine if the respondents were indeed successful when they finally reach the age the agreement must be kept.

We should also mention that we only studied parents and their children with regard to the no-smoking agreement and smoking-specific communication. Although relevant, we cannot speculate what the effects of school-based no-smoking agreement programs are. School-based smoking prevention programs, such as the European Smokefree Class competition, are founded on the idea that risk perception, social norms, personal skills and motivation, attitudes, social support, feedback, and self-efficacy are crucial factors in 
prevention programs (Botvin, 2000; de Vries et al., 2003). These factors are all woven into the design of the program of which the no-smoking agreement is just one aspect.

\section{CONCLUSION AND IMPLICATIONS FOR PRACTICE}

However, some suggestions with regard to prevention can be made based on our findings. At this point in time, the idea that the "no-smoking agreement" is an effective parental strategy to deal with adolescent smoking is not supported by the two longitudinal studies presented in this article. Second, if parents are motivated to prevent smoking in their children, they might be helped with communication skills training in which they can learn to fine-tune their communication to the needs of their child. This sort of communication reflects respect, helps mutual trust to grow, and avoids an atmosphere of frequent nagging about smoking issues. Our study demonstrates that parents who want to prevent their early adolescent children from smoking should focus their efforts on good quality communication about the subject. High-quality communication seems to contain the positive aspects that are considered very important in parenting literature. This study demonstrates that parents who just talk a lot about smoking issues without considering the quality of their communication might do more harm than good.

\section{References}

Aguinis, R. (2004). Regression analysis for categorical moderators. New York: Guilford Press. Bandura, A. (1986). Social foundations of thought and action: A social cognitive theory. Englewood Cliffs, NJ: Prentice-Hall.

Botvin, G. J. (2000). Preventing drug abuse in schools: Social and competence enhancement approaches targeting individual-level etiologic factors. Addictive Behaviors, 25, 887-897.

Chassin, L., Presson, C. C., Rose, J., Sherman, S. J., Davis, M. L., \& Gonzalez, J. L. (2005). Parenting style and smoking-specific parenting practices as predictors of adolescent smoking onset. Journal of Pediatric Psychology, 30, 333-344.

Chassin, L., Presson, C. C., Sherman, S. J., \& Edwards, D. A. (1990). The natural history of cigarette smoking: Predicting young-adult smoking outcomes from adolescent smoking patterns. Health Psychology, 9, 701-716.

Clark, P. I., Scarisbrick-Hauser, A., Gautam, S. P., \& Wirk, S. J. (1999). Anti-tobacco socialization in homes of African-American and White parents, and smoking and nonsmoking parents. Journal of Adolescent Health, 24, 329-339.

den Exter Blokland, E. A. W., Engels, R. C. M. E., Hale, W. W., III, Meeus, W., \& Willemsen, M. C. (2004). Lifetime parental smoking history and cessation and early adolescent smoking behaviour. Preventive Medicine, 38, 359-368.

den Exter Blokland, E. A. W., Hale, W.W., III, Meeus, W., \& Engels, R. C. M. E. (2006). Parental anti smoking socialization and adolescent smoking onset. European Addiction Research, 12, 25-32.

de Vries, H., Mudde, A., Leijs, I., Charlton, A., Vartiainen, E., Buijs, G., et al. (2003). The European Smoking Prevention Framework Approach (EFSA): An example of integral prevention. Health Education Research, 18, 611-626.

Dishion, T. J., \& McMahon, R. J. (1998). Parental monitoring and the prevention of child and adolescent problem behavior: A conceptual and empirical formulation. Clinical Child and Family Psychology Review, 1, 61-75.

Engels, R. C. M. E., Knibbe, R. A., \& Drop, M. J. (1999). Predictability of smoking in adolescence: Between optimism and pessimism. Addiction, 94, 115-124. 
Engels, R. C. M. E., Vitaro, F., den Exter Blokland, A., De Kemp, R., \& Scholte, R. (2004). Parents, friendship selection processes and adolescent smoking behavior. Journal of Adolescence, 27, 531-544.

Engels, R. C. M. E., \& Willemsen, M. (2004). Communication about smoking in Dutch families: Associations between anti-smoking socialization and adolescent smoking-related cognitions. Health Education Research, 19, 227-238.

Ennett, S. T., Bauman, K. E., Foshee, V. A., Pemberton, M., \& Hicks, K. A. (2001). Parent-child communication about adolescent tobacco and alcohol use: What do parents say and does it affect youth behavior? Journal of Marriage and the Family, 63, 48-62.

Fagerstrom, K. O. (1991). Towards better diagnoses and more individual treatment of tobacco dependence. British Journal of Addiction, 86, 543-547.

Harakeh, Z., Engels, R. C. M. E., De Vries, H., \& Scholte, R. (2006). Correspondence between proxy and self-reports on smoking in a full family study. Drugs and Alcohol Dependence, 84, 40-47.

Harakeh, Z., Scholte, R., De Vries, H., \& Engels, R. C. M. E. (2005). Parental rules and communication: their association with adolescent smoking. Addiction, 100, 862-870.

Harakeh, Z., Scholte, R., De Vries, H., Vermulst, A., \& Engels, R. C. M. E. (2004). Parental factors, smoking specific cognitions and early onset of smoking. Preventive Medicine, 39, 951-961.

Henriksen, L., \& Jackson, C. (1998). Anti-smoking socialization: Relationship to parent and child smoking status. Health Communication, 10, 87-101.

Hill, K. G. J., Hawkins, D., Catalano, R. F., Abbott, R. D., \& Guo, J. (2005). Family influences on the risk of daily smoking initiation. Journal of Adolescent Health, 37, 202-210.

Jackson, C. (1997). Initial and experimental stages of tobacco and alcohol use during late childhood: relation to peer, parent, and personal risk factors. Addictive Behaviors, 22, 685-698.

Jackson, C., \& Henriksen, L. (1997). Do as I say: parent smoking, antismoking socialization, and smoking onset among children. Addictive Behaviour, 22, 107-114.

Kerr, M., Statin, H., \& Trost, K. (1999). To know you is to trust you: parents' trust is rooted in child disclosure of information. Journal of Adolescence, 22, 737-752.

Kodl, M. M., \& Mermelstein, R. (2004). Beyond modeling: Parenting practices, parental smoking history, and adolescent cigarette smoking. Addictive Behaviors, 29, 17-32.

Kremers, S. P. J., Mudde, A. N., \& de Vries, H. (2001). Kicking the initiation: Do adolescent ex-smokers differ from other groups within the initiation continuum? Preventive Medicine, 33, 392-401.

Otten, R., Harakeh, Z., Vermulst, A. A., Van Den Eijnden, R. J. J. M., \& Engels, R. C. M. E., (2007). Frequency and quality of parental communication as antecedents of adolescent smoking cognitions, and smoking onset. Psychology of Addictive Behaviors, 21, 1-12.

Stanton, W. R. (1995). DSM-III-R tobacco dependence and quitting during late adolescence. Addictive Behaviors, 20, 595-603.

Van Der Vorst, H., Engels, R. C. M. E., Deković, M., Van Leeuwe, J., \& Meeus, W. (2005). The role of alcohol specific socialization on adolescents' drinking behavior. Addiction, 100, 1464-1474.

Vink, J. M., Willemsen, G., Engels, R. C. M. E., \& Boomsma, D. (2003). Does the smoking behavior of parents, siblings and friends influence smoking behavior in adolescent twins? Twin Research, 6, 209-217. 